\title{
A comparison of flight energetics and kinematics of migratory Brambling and residential Eurasian Tree Sparrow
}

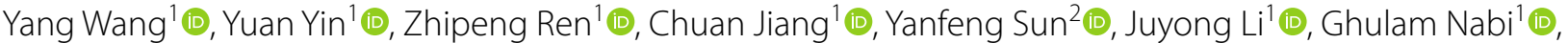 \\ Yuefeng $\mathrm{Wu}^{1} \mathbb{D}$ and Dongming $\mathrm{Li}^{1^{*}}$ (B)
}

\begin{abstract}
Background: Unlike resident birds, migratory birds are generally believed to have evolved to enhance flight efficiency; however, direct evidence is still scarce due to the difficulty of measuring the flight speed and mechanical power.

Methods: We studied the differences in morphology, flight kinematics, and energy cost between two passerines with comparable size, a migrant (Fringilla montifringilla, Brambling, BRAM), and a resident (Passer montanus, Eurasian Tree Sparrow, TRSP).

Results: The BRAM had longer wings, higher aspect ratio, lower wingbeat frequency, and stroke amplitude compared to the TRSP despite the two species had a comparable body mass. The BRAM had a significantly lower maximum speed, lower power at any specific speed, and thus lower flight energy cost in relative to the TRSP although the two species had a comparable maximum vertical speed and acceleration.

Conclusions: Our results suggest that adaptation for migration may have led to reduced power output and maximum speed to increase energy efficiency for migratory flight while residents increase flight speed and speed range adapting to diverse habitats.
\end{abstract}

Keywords: Flight energy efficiency, Flight kinematics, Flight speed, Maximum load-lifting capacity

\section{Background}

Flight performance is a fundamental factor for fitness in ecological and evolutionary contexts (Webster et al. 2002; Bauer and Hoye 2014). According to the theory of migration syndrome (Bauchinger et al. 2005; Hedenström 2008), migratory birds have evolved a suite of modifications in wing morphology and kinematics in terms of energy consumption for long-journey flight than residents (Hedenström 2008; van Oorschot et al. 2016). For

\footnotetext{
${ }^{*}$ Correspondence: lidongming@hebtu.edu.cn

${ }^{1}$ Key Laboratory of Animal Physiology, Biochemistry and Molecular

Biology of Hebei Province, College of Life Sciences, Hebei Normal University, Shijiazhuang 050024, China

Full list of author information is available at the end of the article
}

example, migratory birds not only have highly efficient wings (more prolonged and narrower wings, lower wing loading) but also exhibit lowered wingbeat frequency and stroke amplitude for continuous flight avoiding additional parasite drag relative to residents (Minias et al. 2015; Grilli et al. 2017). Given that it is difficult to directly measure these parameters under the natural conditions (Zhao et al. 2017; Horton et al. 2018), little information is available on how migratory birds adjust airspeed and mechanical power relative to residents.

Considering that power consumption follows a U-shaped relationship with flight speed, fly at a speed too low or high than usual will demand an extra amount of energy and lower energy efficiency (Alerstam et al. 2007; 
Alerstam 2011). Theoretically, small migratory birds should fly at speed with the maximum range speed $\left(V_{\mathrm{mr}}\right)$ and maximize the efficiency of flight to meet the strategy of energy-minimization during the flight (Hedenström 2002; Tobalske et al. 2003). By contrast, residents are less constrained by the energy demand of long-distance flight, and a higher maximum speed $\left(V_{\max }\right)$ can improve chasing and escaping ability (Clemente and Wilson 2016, Fig. 1).

The maximum load-lifting capacity experiment (as imposed via asymptotic loading) is a quantifiable way to determine maximum flight performance and estimate maximum power available during the flight in volant animals (Marden 1987; Altshuler et al. 2010). By measuring flight-related morphology, kinematics, and maximum weight lifted during maximum load-lifting flight trials, we can calculate aerodynamic power output with aerodynamic model and estimate flight speed $\left(V_{\mathrm{mr}}\right.$ and $\left.V_{\max }\right)$. Specifically, $V_{\mathrm{mr}}$ is calculated with flight-related morphology and optimized kinematics; $V_{\max }$ is the maximal flight speed supported by maximal available output power in load-lifting flight trials (Pennycuick 2008). The minimal flight energy cost at a certain distance (Distance $\times P_{\text {fight }} / V_{\mathrm{mr}}$, i.e., power cost per $100 \mathrm{~km}$ per unit body mass) can provide a framework to investigate the airborne energy consumption of transport. Measuring the vertical speed, acceleration during load-free flight trials, and power margin (the excess available aerodynamic power for vertical ascent) can evaluate the maneuverability of birds (Altshuler et al. 2004).

Passerines (Passeriformes, Aves) are typically featured with flapping flight that have higher power requirements than those birds with other flight modes (e.g., soaring, gliding). Therefore, passerines are under more selective pressures of optimizing flight speed and energy consumption (Gavrilov 2011; Vincze et al. 2018). To test the hypothesis that migrants would enhance the energy efficiency at $V_{\mathrm{mr}}$, and residents would have high $V_{\max }$ to improve maneuverability (Chernetsov 2012). We compared the differences in flight speed and energy efficiency between two passerines with a resident species (Passer montanus, Eurasian Tree Sparrow, TRSP) and a migratory species (Fringilla montifringilla, Brambling, BRAM). We predicted that (1) BRAM would have a higher $V_{\mathrm{mr}}$ and a better flight efficiency to meet the time- and

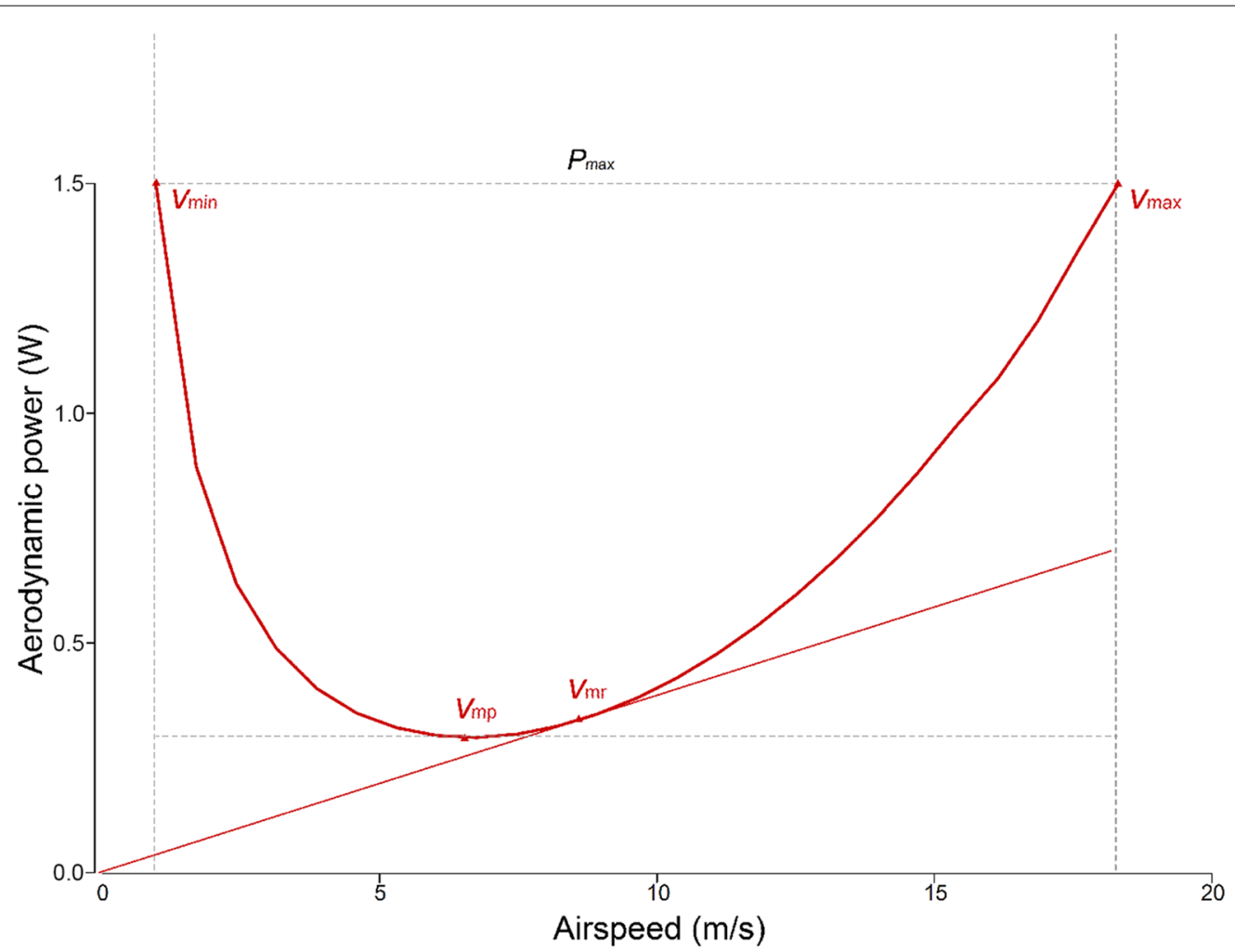

Fig. 1 The relationship between airspeed and the aerodynamic power requirement during flight (Pennycuick 2008; Klein et al. 2015). At minimum speed $\left(V_{\min }\right)$ and maximum speed $\left(V_{\max }\right)$, the required aerodynamic power equals the maximum available power output. At minimum power speed $\left(V_{\mathrm{mp}}\right)$ is when the required aerodynamic power is minimal (the speed for maximum endurance). At maximum range speed $\left(V_{\mathrm{mr}}\right)$ is when the cost of transport is minimal (the speed for maximum range) 
energy- minimization of migration (Alerstam 2011); (2) TRSP would flight at a higher $V_{\max }$ to achieve better maneuverability for local competition and anti-predation, with a lower flight efficiency (Askew and Ellerby 2007).

\section{Methods}

\section{Study species}

The BRAM is a small passerine migrant which can migrate as far as $3600 \mathrm{~km}$ (Fang et al. 2008; see distribution map in Fig. 2) with comparable body size ( $\sim 21 \mathrm{~g})$, similar diets (seeds and invertebrates), and habitats (forests, shrublands, and artificial; Snow and Perrins 1998; Summers-Smith 2016) as the TRSP (common resident species with broad distribution range, Sun et al. 2017; Li et al. 2019).

\section{Birds collection}

The TRSP $(n=13)$ and BRAM $(n=8)$ were captured opportunistically using mist nets from March 13 to April 1, 2017, at the campus of Hebei Normal University ( $37^{\circ} 59.88 \mathrm{~N}, 114^{\circ} 31.18 \mathrm{E}$, elevation: $\left.72 \mathrm{~m}\right)$, Shijiazhuang, China. Within 30 min post-capture, body mass was measured with a portable digital balance for each bird to the nearest $0.01 \mathrm{~g}$ and transferred to the university laboratory for determining their maximum flight capacity within $2-4 \mathrm{~h}$.

\section{Maximum load-lifting assay and wing kinematics}

Each bird was evaluated for asymptotic load-lifting capacity in a rectangular flight chamber using a maximum load-lifting approach described in detail by Sun et al. (2016) and Wang et al. (2019). In brief, one highspeed video camera (GCP100BAC, JVC Kenwood Corporation, Yokohama, Japan; operated at 250 frames $^{-1}$ ) placed on the top of the chamber was used to obtain wingbeat frequency and stroke amplitude (Additional file 1: Movie S1). The other synchronized camera (operated at 50 frames $^{-1}$ ) positioned laterally at a distance of $80 \mathrm{~cm}$ to the chamber was used to record the beads remaining on the chamber floor during the maximum load-lifting flight (Additional file 2: Movie S2).

The maximum lifted weight was calculated by the total weight of beads subtraction to the weight of remaining beads on the chamber floor when peak lifting was achieved. The sum of bodyweight gave the maximum load (total lifted load) and the maximum lifted weight. A time-averaged wingbeat frequency was determined by the interaction frequency between wing motions and the camera filming speed over the same measurement period. Wing stroke amplitude was derived from video

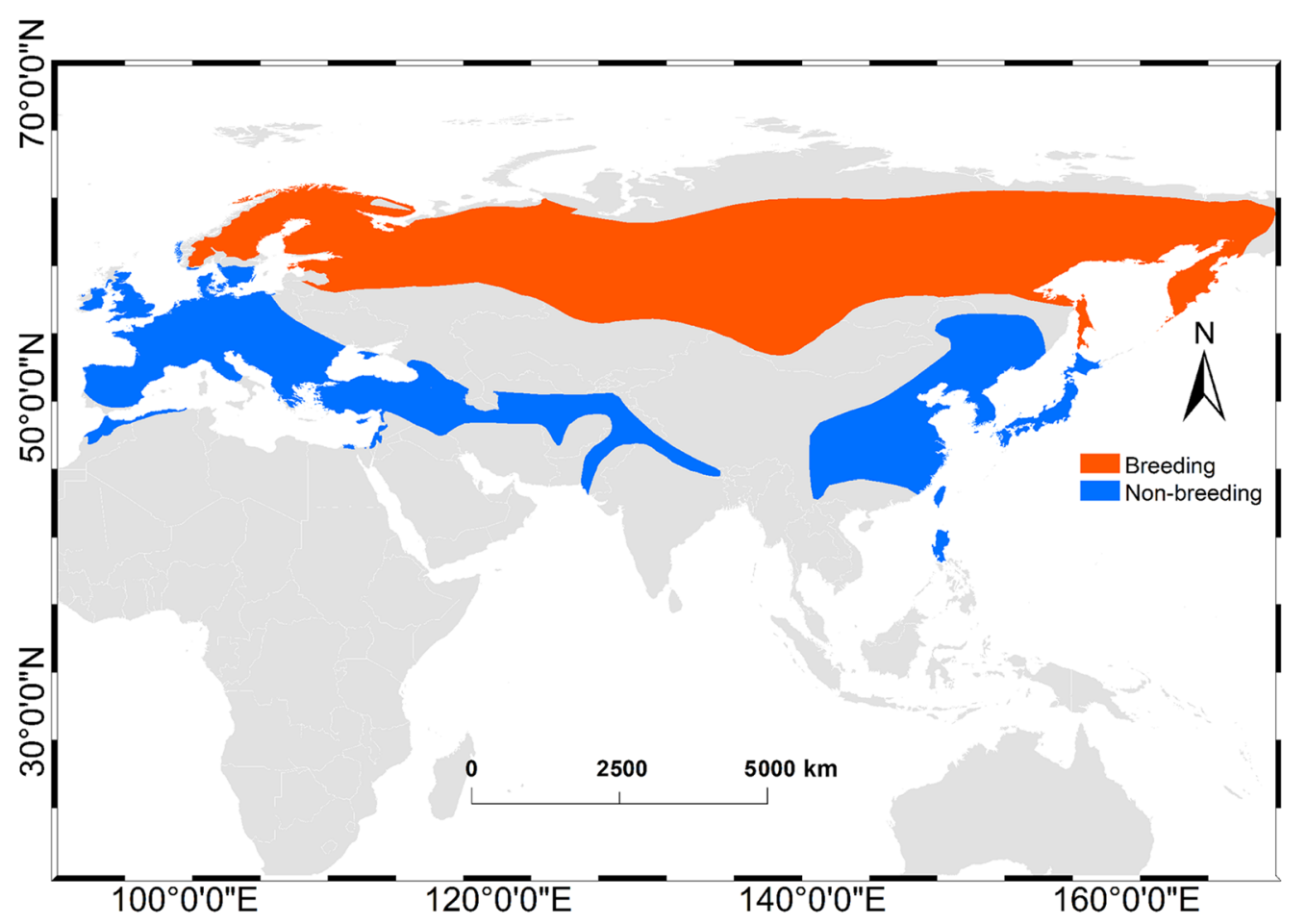

Fig. 2 Breeding and non-breeding distribution ranges of Fringilla montifringilla (Brambling, BRAM; extracted from BirdLife International 2019) 
Table 1 Statistical results of flight-related morphology, load-lifting capacity, flight kinematics, flight speed and energy efficiency between Fringilla montifringilla (Brambling, BRAM; $n=8$ ) and Passer montanus (Eurasian Tree Sparrow, TRSP; $n=13$ ) in independent $t$-tests or Mann-Whitney $U$ tests

\begin{tabular}{|c|c|c|c|}
\hline Type of variable & Variable & $t$ value & $P$ value \\
\hline \multirow[t]{5}{*}{ Flight-related morphology } & Body mass (g) & 0.569 & 0.576 \\
\hline & Wing length (mm) & 16.69 & $<0.001$ \\
\hline & Wing area $\left(\mathrm{cm}^{2}\right)$ & 6.158 & $<0.001$ \\
\hline & Wing loading $\left(\mathrm{N} / \mathrm{m}^{2}\right)$ & 4.326 & $<0.001$ \\
\hline & Aspect ratio & 5.024 & $<0.001$ \\
\hline \multirow[t]{3}{*}{ Load-lifting capacity } & Maximum load (g) & 1.321 & 0.202 \\
\hline & Mass-corrected maximum load & 2.040 & 0.056 \\
\hline & Maximum wing loading $\left(\mathrm{N} / \mathrm{m}^{2}\right)$ & 4.326 & $<0.001$ \\
\hline \multirow[t]{2}{*}{ Flight kinematics } & Wingbeat frequency $(\mathrm{Hz})$ & 6.627 & $<0.001$ \\
\hline & Wing stroke amplitude (deg) & 2.691 & 0.015 \\
\hline \multirow[t]{5}{*}{ Flight performance } & Maximum vertical speed (m/s) & 0.625 & 0.540 \\
\hline & Maximum vertical acceleration $\left(\mathrm{m} / \mathrm{s}^{2}\right)$ & 0.171 & 0.866 \\
\hline & Power margin & 0.641 & 0.529 \\
\hline & Maximum range speed $\left(V_{\mathrm{m} r} \mathrm{~m} / \mathrm{s}\right)$ & 8.298 & $<0.001$ \\
\hline & Maximum speed $\left(V_{\max ,} \mathrm{m} / \mathrm{s}\right)$ & 8.176 & $<0.001$ \\
\hline \multirow[t]{10}{*}{ Flight energy efficiency } & Power at $V_{\mathrm{mr}}(\mathrm{W})^{\mathrm{a}}$ & 5.914 & $<0.001$ \\
\hline & Power at $V_{\max }(\mathrm{W})$ & 6.266 & $<0.001$ \\
\hline & Mass-corrected power at $V_{\mathrm{mr}}(\mathrm{W} / \mathrm{kg})$ & 6.669 & $<0.001$ \\
\hline & Mass-corrected power at $V_{\max }(\mathrm{W} / \mathrm{kg})$ & 7.228 & $<0.001$ \\
\hline & Parasitic drag at $V_{\mathrm{mr}}(\mathrm{N})$ & 5.972 & $<0.001$ \\
\hline & Parasitic drag at $V_{\max }(\mathrm{N})$ & 5.817 & $<0.001$ \\
\hline & Reynolds number at $V_{\mathrm{mr}}$ & 3.336 & 0.003 \\
\hline & Reynolds number at $V_{\max }$ & 3.411 & 0.003 \\
\hline & Mass-corrected power cost per $100 \mathrm{~km}$ at $V_{\mathrm{mr}}(\mathrm{Wh} / \mathrm{kg})^{\mathrm{a}}$ & 7.901 & $<0.001$ \\
\hline & Mass-corrected power cost per $100 \mathrm{~km}$ at $V_{\max }(\mathrm{Wh} / \mathrm{kg})$ & 9.544 & $<0.001$ \\
\hline
\end{tabular}

Italic values indicate significance of $P$ value $(P<0.05)$

a Variables were compared by the Mann-Whitney $U$ test

images in which the wings were located at the extreme positions of the wingbeat within each bout of final $0.5 \mathrm{~s}$ of maximum load-lifting. Multiple ascending flights were recorded for each bird (mean of 4.1 flights), and the maximum weight lifted within the series was assumed to indicate the limit to load-lifting of flight performance. All birds were released after completing all measurements and flight trails (5-6 h post-capture).

\section{Flight-related morphology}

Following load-lifting experiments, flight-related morphological traits were measured to the nearest $0.1 \mathrm{~mm}$ using Vernier caliper (Mitutoyo, Kawasaki, Japan). The right-wing of each bird was photographed for measurements of the total wing area $S$ (given by twice the area of the right-wing) and wing length $R$ using ImageJ (National Institutes of Health, Bethesda, MD, USA). The aspect ratio is given by $4 R^{2} / S$. Wing loading was calculated by dividing the body weight by $S$, and maximum wing loading was provided by dividing the total maximum load by $S$. Mass-corrected maximum load was calculated by dividing the total maximum load by body weight.

\section{Flight speed and energy efficiency}

We measured the vertical speed for each individual based on video records of load-free flight trials in the chamber. The whole distance from the floor to the up limits of the flight trials was evenly divided by four or five parts with a length of $20 \mathrm{~cm}$ for each part. The maximum vertical speed and acceleration were calculated as the highest achieved speed and acceleration among all parts for each individual. Maximum power (maximum available muscle power to support the flight) during the maximum load-lifting flight was calculated using Ellington's equation (Ellington 1984) following the method described by Askew and Ellerby (2007). Theoretical $V_{\mathrm{mr}}, V_{\max }$, parasite 

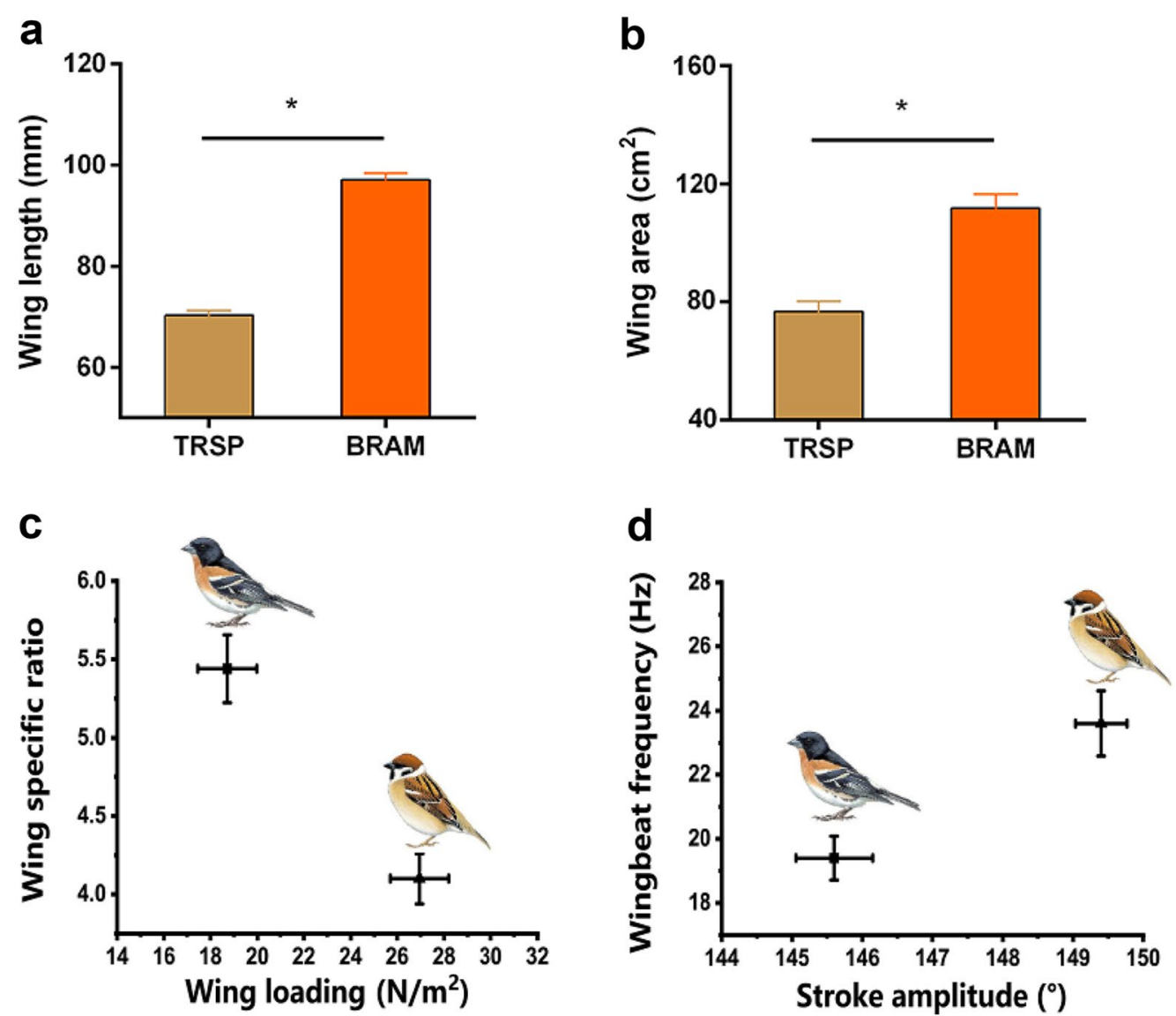

Fig. 3 Comparisons of a wing length ( $\mathrm{mm})$, b wing area $\left(\mathrm{cm}^{2}\right)$, c aspect ratio and wing loading $\left(\mathrm{kg} / \mathrm{m}^{2}\right)$ and $\mathbf{d}$ wingbeat frequency $(\mathrm{Hz})$ and wing stroke amplitude (degree) during the maximum load-lifting flight of Passer montanus (Eurasian Tree Sparrow, TRSP, $n=13$ ) and Fringilla montifringilla (Brambling, BRAM, $n=8$ ). All variables differed significantly between species. All values depicted for each species are the means with standard error, * represents $P<0.05$. Images of each species were taken from https://www.hbw.com/

drag, Reynolds number, and the airborne energy efficiency of transport at $V_{\mathrm{mr}}$ and $V_{\max }$ were calculated using computeFlightPerformance functions in "afpt" package for each individual (Klein et al. 2015) in R software (R Core Team 2018). The power margin was calculated as the difference of maximum power and minimum power required to flight as an estimate of maneuverability.

\section{Statistical analysis}

The homogeneity of variances was tested using Levene's test of equality of variances before analysis. We implemented independent $t$-tests or Mann-Whitney $U$ tests to compare all the variables between species. Statistical analysis was performed using SPSS Statistics 21.0 software (IBM, New York, USA). All data are presented as mean \pm SEM. The significant difference was $P<0.05$.

\section{Results}

The BRAM and TRSP had a comparable body mass, maximum load, and mass-corrected maximum load. However, BRAM had significantly longer and larger wings, higher aspect ratio, smaller wing loading, lower wingbeat frequency, and stroke amplitude compared with TRSP (Table 1; Fig. 3).

The BRAM and TRSP had a comparable maximum vertical speed and acceleration, and power margin (Table 1). However, BRAM had a significantly lower $V_{\mathrm{mr}}$ and $V_{\max }$, power, parasitic drag, Reynolds number, and masscorrected power cost per $100 \mathrm{~km}$ in both $V_{\mathrm{mr}}$ and $V_{\max }$ compared with those of TRSP (Table 1; Figs. 4 and 5). Furthermore, the BRAM had lower flight power, masscorrected flight power, and mass-corrected flight power per $100 \mathrm{~km}$ relative to TRSP at low- and middle-speed ranges (Fig. 5). 

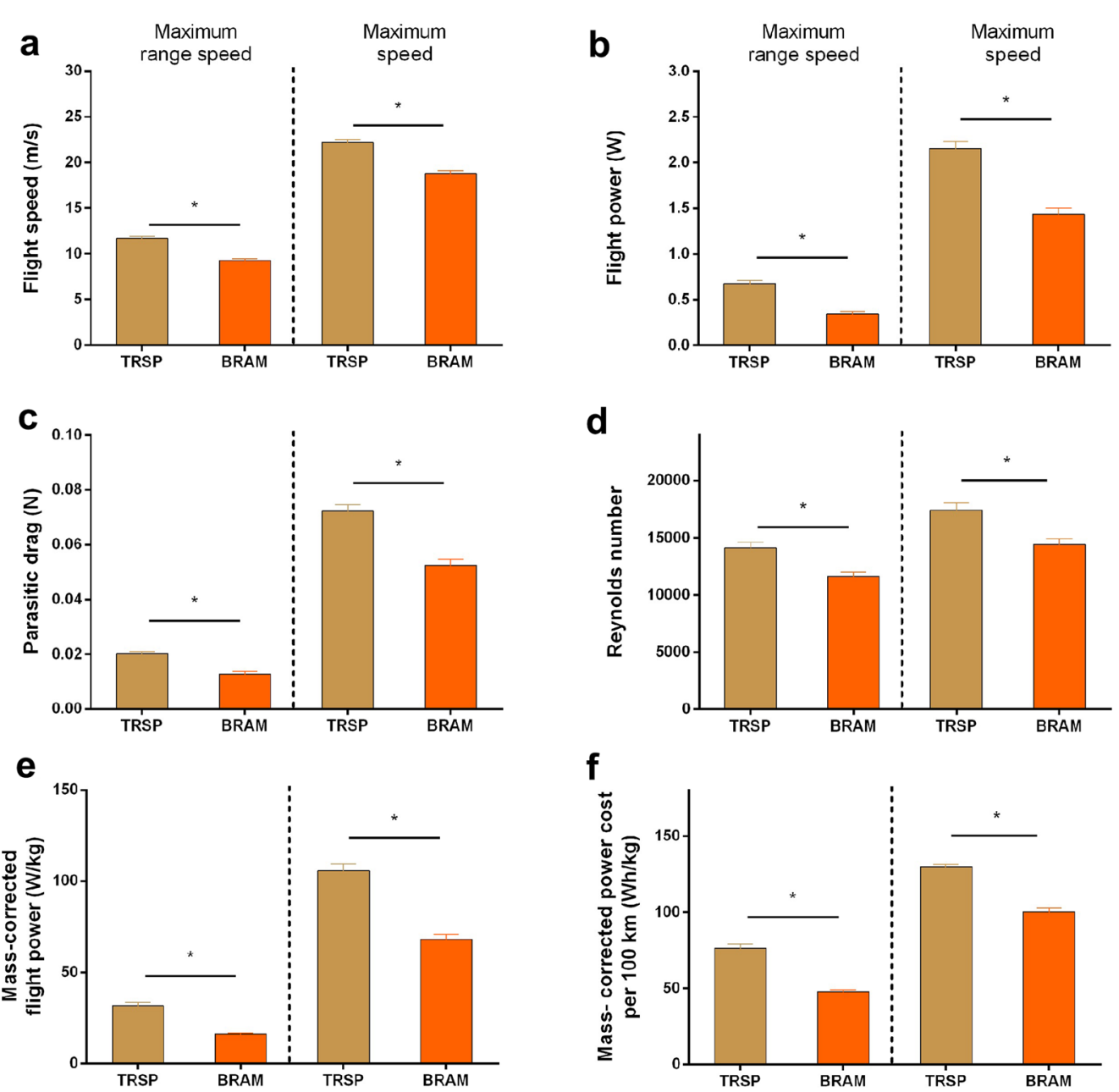

Fig. 4 Comparisons of a flight speed (m/s), b flight power (W), c parasite drag (N), d Reynolds number, e mass-corrected power (W/kg), and $\mathbf{f}$ mass-corrected power cost per $100 \mathrm{~km}(\mathrm{Wh} / \mathrm{kg})$ at maximum range speed $\left(V_{\mathrm{mr}}\right)$ and maximum speed $\left(V_{\max }\right)$ of Passer montanus (Eurasian Tree Sparrow, TRSP, $n=13$ ) and Fringilla montifringilla (Brambling, BRAM, $n=8$ ). All values depicted for each species are the means with standard error, * represents $P<0.05$

\section{Discussion}

By identifying the differences in flight-related morphology, load-lifting capacity, kinematics, and theoretical flight speed and energy efficiency between BRAM and TRSP, we found a significantly lowered $V_{\mathrm{mr}}$ and $V_{\max }$ in BRAM relative to TRSP due to reduced power availability (Fig. 4). The trade-off between time and energy cost during migration is influenced by body size (Zhao et al. 2017), season (Nilsson et al. 2013), distance (Schmaljohann 2018), etc. Our results suggested that migrant passerines may be favored by a higher flight efficiency to achieve an energy- minimization strategy rather than a time-minimization strategy, while residents may be favored by a higher $V_{\max }$ to achieve better maneuverability. Furthermore, the flight energy efficiency was higher in BRAM with lower power requirements (or available power) when flying at any given speed relative to the TRSP, especially at low- and middle-speed ranges (Fig. 5). More importantly, our results found that it is a dilemma for birds to enhance flight speed and efficiency. Therefore, the flight ability of small passerine migrants was more constrained by energy rather than time (lower flight speed and higher energy efficiency).

The wing morphology and behavior of the wing motion of birds are crucial components of powered flight performance and energy efficiency (Alerstam 2011). Morphologically, BRAM had larger and longer wings, and lower wing loading relative to TRSP. Our results confirm that the avian wing has evolved to adapt to their various lifestyles (Dudley 1991; Lockwood 1998). In comparison, 

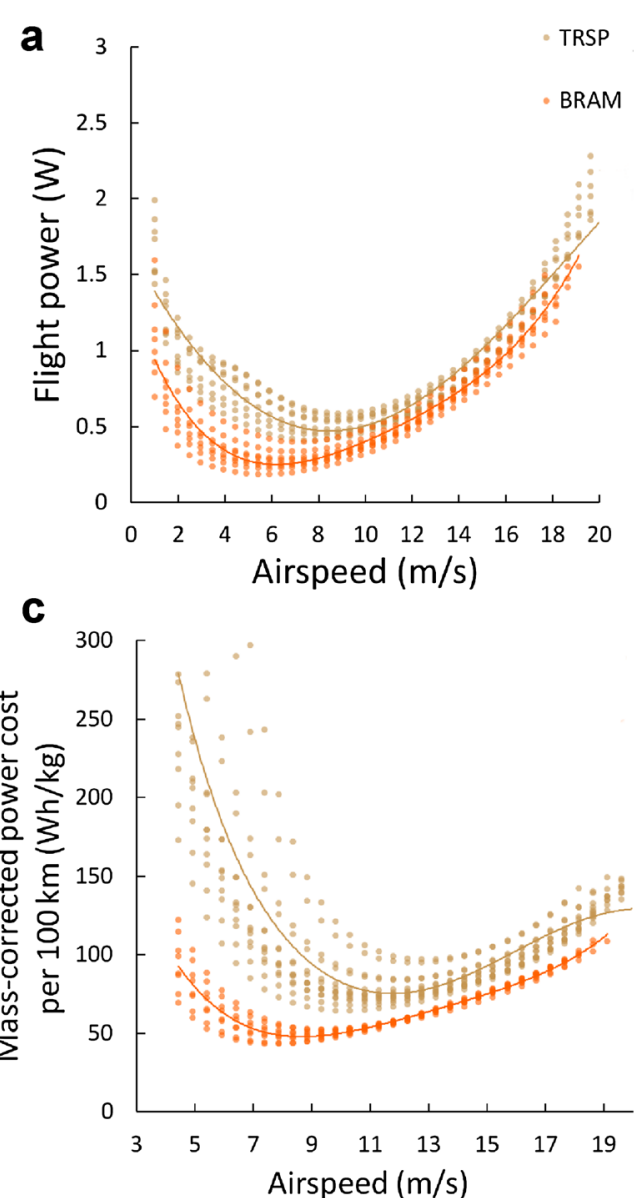

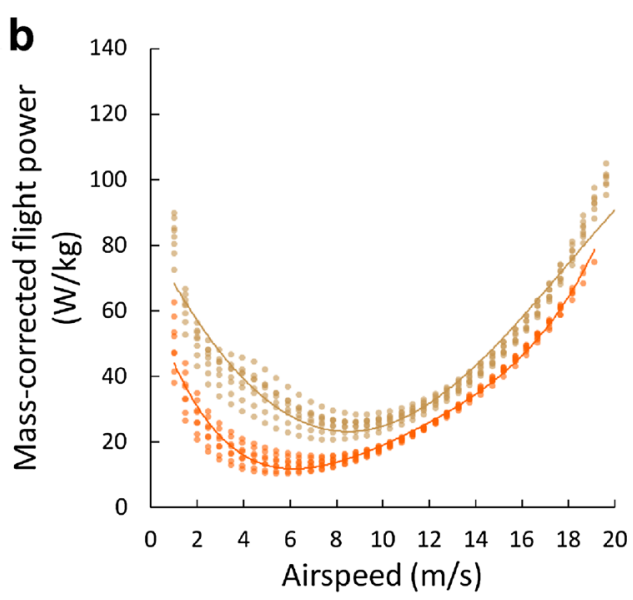
possible speed for Passer montanus (Eurasian Tree Sparrow, TRSP, $n=13$ ) and Fringilla montifringilla (Brambling, BRAM, $n=8$ ). All points represented individuals; polynomial curves are used to fit the trends of each species

migrants had high- efficiency wings for long-journey flight, and residents had high-maneuverability wings for escaping, foraging, etc. (Minias et al. 2015; Grilli et al. 2017). Lowered wingbeat frequency and wing stroke amplitude for BRAM relative to TRSP can be an adaptation for optimizing energy efficiency since aerodynamic power output (Ellington 1984; Pennycuick 2008) and metabolic rates (Bishop et al. 2015) are declining superlinearly with the wingbeat frequency and stroke amplitude. Lowered wing loading of BRAM would require a reduced wingbeat frequency and stroke amplitude to stay airborne, which could be one of the reasons that BRAM showed higher efficiency of powered flight for long-distance migration. Our results provided evidence that the migratory passerines exhibit a higher flight energy efficiency, especially at a lower speed range, and this functional improvement is evolved through the combined adaptive features of wing morphology and kinematics.
Reduction in the flight speed resulted in decreased parasite drag, which could prevent extra flight energy consumption (Pennycuick 2008). Similarly, we found the BRAM exhibited reduced $V_{\mathrm{mr}}$ and $V_{\max }$, and their corresponding parasite drag, Reynolds number, and efficiency of transport (mass-corrected power cost per $100 \mathrm{~km}$ ) relative to the TRSP. The BRAM had a higher energy efficiency of flight, especially at a low- and middle- speed range (Fig. 5), which may be an ecological strategy for reducing extra energy cost during takingoff and escaping flight. By contrast, the TRSP with significantly higher power may be essential to enhance the flight speed range (Askew and Ellerby 2007), since the residents cannot mitigate the competition and predation through seasonal migration. Therefore, migrant passerines enhanced flight energy efficiency not only through lowering flight speed but energy efficiency at a given speed, resulting from a suite of alternations in function-based morphology and kinematics 
(mentioned above) relative to residents. Our results further suggest that migrants would increase their flight efficiency without compromising flight maneuverability during takeoff since the vertical speed and power margin are comparable between migrants and residents. However, lower maximum speed for the migrants may also decrease the success rates of escape in extreme conditions compared with residents (Clemente and Wilson 2016).

\section{Conclusions}

In summary, our results indicate that migrants exhibit the feature of reduced flight power with the lower cost for flight energy and maneuverability. On the other hand, residents exhibit the opposite direction of increasing flight power that is critical for enhancing maximum flight speed and power to widen speed range for predator escaping and local competition. Our findings support the notion that migratory passerines have acquired a better airborne energy efficiency through a series of adaptive changes on flight-related morphology and kinematics. However, these morphological and kinematic adaptations are still not enough to increase both flight speed and efficiency concurrently. Migrants are under the selection of balancing time and energy consumption of the long-distance migration during their long-distance migration (energy seems more vital for BRAM). Further investigations are needed to include multiple avian taxonomies for exploring potential phylogenetic effects and their metabolic and molecular alternations to expand our understanding of evolution in the efficiency of airborne travel.

\section{Supplementary information}

Supplementary information accompanies this paper at https://doi. org/10.1186/s40657-020-00211-y.

Additional file 1: Movie S1.TRSP top view.

Additional file 2: Movie S2. TRSP side view.

\section{Acknowledgements}

We appreciate the help of Mr. Guanqun Kou for sample and video collection.

\section{Authors' contributions}

$\mathrm{DL}$ and $Y W u$ conceived the ideas and designed the study; YWang, YY, ZP, YS, and $\mathrm{J}$ conducted the experiment and collected the data; YWang carried out the statistical analyses with the help of $\mathrm{CJ} ; \mathrm{DL}, \mathrm{YWu}$, and $\mathrm{GN}$ wrote the manuscript. All authors read and approved the final manuscript.

\section{Funding}

This study was funded by the National Natural Science Foundation of China (NSFC, 31672292) to DL, NSFC (31770445) to Y. Wu, NSFC (31800338) and the Foundation of Hebei Normal University (L042017B03) to Y. Wang.

\section{Availability of data and materials}

Our additional materials are available online.

\section{Ethics approval and consent to participate}

All protocols were approved by the Ethics and Animal Welfare Committee (no. 2013-6) and by the Institutional Animal Care and Use Committee (HEBTU20137) of Hebei Normal University, China, and were carried out under the auspices of scientific collecting permits issued by the Department of Wildlife Conservation (Forestry Bureau) of Hebei Province, China.

\section{Consent for publication}

Not applicable.

\section{Competing interests}

The authors declare that they have no competing interests.

\section{Author details}

${ }^{1}$ Key Laboratory of Animal Physiology, Biochemistry and Molecular Biology of Hebei Province, College of Life Sciences, Hebei Normal University, Shijiazhuang 050024, China. ${ }^{2}$ Ocean College of Hebei Agricultural University, Qinhuangdao 066003, China.

Received: 29 February 2020 Accepted: 12 July 2020

Published online: 19 July 2020

\section{References}

Alerstam T. Optimal bird migration revisited. J Ornithol. 2011;152:5-23.

Alerstam T, Rosén M, Bäckman J, Ericson PG, Hellgren O. Flight speeds among bird species: allometric and phylogenetic effects. PLoS Biol. 2007:5:e197.

Altshuler DL, Dudley R, McGuire JA. Resolution of a paradox: hummingbird flight at high elevation does not come without a cost. Proc Natl Acad Sci USA. 2004:101:17731-6.

Altshuler D, Dudley R, Heredia S, McGuire J. Allometry of hummingbird lifting performance. J Exp Biol. 2010;213:725-34.

Askew GN, Ellerby DJ. The mechanical power requirements of avian flight. Biol Lett. 2007:3:445-8.

Bauchinger U, Both C, Piersma T. Are there specific adaptations for longdistance migration in birds? The search for adaptive syndromes-outline of the European Science Foundation Workshop. Ann NY Acad Sci. 2005:1046:214-5.

Bauer S, Hoye BJ. Migratory animals couple biodiversity and ecosystem functioning worldwide. Science. 2014;344:1242552.

Bishop CM, Spivey RJ, Hawkes LA, Batbayar N, Chua B, Frappell PB, et al. The roller coaster flight strategy of bar-headed geese conserves energy during Himalayan migrations. Science. 2015:347:250-4.

Chernetsov N. Optimal migration theory. Berlin: Springer; 2012. p. 19-50.

Clemente CJ, Wilson RS. Speed and maneuverability jointly determine escape success: exploring the functional bases of escape performance using simulated games. Behav Ecol. 2016;27:45-54.

Dudley R. Biomechanics of flight in neotropical butterflies: aerodynamics and mechanical power requirements. J Experim Biol. 1991;159:335-57.

Ellington C. The aerodynamics of hovering insect flight. III. Kinematics. Philos T R Soc B. 1984;305:41-78.

Fang KL, Li XD, Guo YM, Li F, Yu XD. Migration of brambling (Fringilla montifringilla) in Gaofeng forestry area of Nenjiang district. Chin J Wildlife. 2008;29:121-3.

Gavrilov VM. Energy expenditures for flight, aerodynamic quality, and colonization of forest habitats by birds. Biol Bull. 2011;38:779-88.

Grilli MG, Lambertucci SA, Therrien JF, Bildstein KL. Wing size but not wing shape is related to migratory behavior in a soaring bird. J Avian Biol. 2017:48:669-78.

Hedenström A. Aerodynamics, evolution and ecology of avian flight. Trends Ecol Evol. 2002;7:415-22.

Hedenström A. Adaptations to migration in birds: behavioural strategies, morphology and scaling effects. Philos T R Soc A. 2008;363:287-99.

Horton KG, Van Doren BM, La Sorte FA, Fink D, Sheldon D, Farnsworth A, et al. Navigating north: how body mass and winds shape avian flight behaviours across a North American migratory flyway. Ecol Lett. 2018:21:1055-64

Klein HM, Johansson LC, Hedenstrom A. Power of the wingbeat: modelling the effects of flapping wings in vertebrate flight. Proc R Soc Lond A. 2015;471:20140952. 
Li M, Zhu W, Wang Y, Sun Y, Li J, Liu X, et al. Effects of capture and captivity on plasma corticosterone and metabolite levels in breeding Eurasian Tree Sparrows. Avian Res. 2019;10:16.

Lockwood R. Avian wingtip shape reconsidered: wingtip shape indices and morphological adaptations to migration. J Avian Biol. 1998;29:273-92.

Marden $\mathrm{H}$. Maximum lift production during takeoff in flying animals. J Exp Biol. 1987;130:235-58.

Minias P, Meissner W, Wlodarczyk R, Ozarowska A, Piasecka A, Kaczmarek K, et al. Wing shape and migration in shorebirds: a comparative study. Ibis. 2015; 157:528-35.

Nilsson C, Klaassen RHG, Alerstam T. Differences in speed and duration of bird migration between spring and autumn. Am Nat. 2013;181:837-45.

Pennycuick CJ. Modelling the flying bird. London: Academic Press; 2008.

R Core Team. R: a language and environment for statistical computing. R foundation for statistical computing, Vienna; 2018. https://www.R-proje ct.org/.

Schmaljohann H. Proximate mechanisms affecting seasonal differences in migration speed of avian species. Sci Rep. 2018;8:4106.

Snow DW, Perrins CM. The birds of the Western Palearctic, volume 2: Passerines. Oxford: Oxford University Press; 1998.

Summers-Smith D. Eurasian tree sparrow (Passer montanus). In: del Hoyo J, Elliott A, Sargatal J, Christie DA, de Juana E, editors. Handbook of the birds of the World Alive. Barcelona: Lynx edicions; 2016.
Sun Y, Ren Z, Wu Y, Lei F, Dudley R, Li D. Flying high: limits to flight performance by sparrows on the Qinghai-Tibet Plateau. J Exp Biol. 2016;219:3642-8.

Sun Y, Li M, Song G, Lei F, Li D, Wu Y. The role of climate factors in geographic variation in body mass and wing length in a passerine bird. Avian Res. 2017;8:1.

Tobalske BW, Hedrick TL, Biewener AA. Wing kinematics of avian flight across speeds. J Avian Biol. 2003;34:177-84.

van Oorschot BK, Mistick EA, Tobalske BW. Aerodynamic consequences of wing morphing during emulated takeoff and gliding in birds. J Exp Biol. 2016;219:3146-54.

Vincze O, Vagasi CI, Pap PL, Palmer C, Moller AP. Wing morphology, flight type and migration distance predict accumulated fuel load in birds. J Exp Biol. 2018;222:jeb183517.

Wang Y, Yin Y, Ge SY, Li M, Zhang Q, Li JY, et al. Limits to load-lifting performance in a passerine bird: the effects of intraspecific variation in morphological and kinematic parameters. PeerJ. 2019;7:e8048.

Webster MS, Marra PP, Haig SM, Bensch S, Holmes RT. Links between worlds: unraveling migratory connectivity. Trends Ecol Evol. 2002;17:76-83.

Zhao M, Christie M, Coleman J, Hassell C, Gosbell K, Lisovski S, et al. Time versus energy minimization migration strategy varies with body size and season in long-distance migratory shorebirds. Mov Ecol. 2017;5:23.
Ready to submit your research? Choose BMC and benefit from:

- fast, convenient online submission

- thorough peer review by experienced researchers in your field

- rapid publication on acceptance

- support for research data, including large and complex data types

- gold Open Access which fosters wider collaboration and increased citations

- maximum visibility for your research: over 100M website views per year

At BMC, research is always in progress.

Learn more biomedcentral.com/submissions 